\title{
Planning of Aegean Archipelago Interconnections to the Continental Power System of Greece ${ }^{\dagger}$
}

\author{
Michalis E. Karystianos ${ }^{1}$, Charalampos N. Pitas ${ }^{1, * \mathbb{D}}$, Stamatina P. Efstathiou ${ }^{1}$, Marina A. Tsili ${ }^{1}$, \\ John C. Mantzaris ${ }^{1}$, Eirini A. Leonidaki ${ }^{2}$, Emmanouil M. Voumvoulakis ${ }^{2}$ and Nikos G. Sakellaridis ${ }^{2}$
}

1 Independent Power Transmission Operator (IPTO-ADMIE), 89 Dyrrachiou Str., 10443 Athens, Greece; MKarystianos@admie.gr (M.E.K.); MEustathiou@admie.gr (S.P.E.); MTsili@admie.gr (M.A.T.); I.Mantzaris@admie.gr (J.C.M.)

2 Hellenic Electricity Distribution Network Operator (HEDNO-DEDDIE), 24 Syngrou Av., 11742 Athens, Greece; E.Leonidaki@deddie.gr (E.A.L.); E.Voumvoulakis@deddie.gr (E.M.V.); N.Sakellaridis@deddie.gr (N.G.S.)

* Correspondence: C.Pitas@admie.gr; Tel.: +30-21-0519-2238

$+\quad$ This article is an extended version of our paper "Planning of the North-East Aegean and Dodecanese islands interconnections to the continental power system: Technical and economic assessment of the interconnection scenaria" published in the Proceedings of the 30th Cigré Greece National Conference "e-Session 2020: Transmission and Distribution Challenges in Greece", Athens, Greece, 26 November 2020; pp. 1-13.

check for updates

Citation: Karystianos, M.E.; Pitas, C.N.; Efstathiou, S.P.; Tsili, M.A.; Mantzaris, J.C.; Leonidaki, E.A.; Voumvoulakis, E.M.; Sakellaridis, N.G. Planning of Aegean Archipelago Interconnections to the Continental Power System of Greece. Energies 2021, 14, 3818. https://doi.org/ 10.3390/en14133818

Academic Editor: Tomislav Capuder

Received: 29 April 2021

Accepted: 16 June 2021

Published: 24 June 2021

Publisher's Note: MDPI stays neutral with regard to jurisdictional claims in published maps and institutional affiliations.

Copyright: (c) 2021 by the authors. Licensee MDPI, Basel, Switzerland. This article is an open access article distributed under the terms and conditions of the Creative Commons Attribution (CC BY) license (https:/ / creativecommons.org/licenses/by/ $4.0 /)$.

\begin{abstract}
This paper presents the results of a thorough planning investigation carried out by the Transmission System Operator (TSO) and the Distribution Network Operator (DNO) in Greece in order to study the interconnections of the Aegean Islands with the mainland power system. The feasibility of interconnecting islands is based on the need for a reliable power supply to isolated and autonomous islands, reducing the operating costs of the power generation system through the withdrawal of high-cost oil-fired generating units, and the further ability to increase renewable energy source (RES) penetration in the country's energy mix, according to directions imposed by the National Energy and Climate Plan. Among the alternative topologies and interconnection technologies considered, the final selection of the interconnection scheme selected for inclusion in the development plans of TSO and DNO was based on their detailed comparative evaluation, considering financial and other technical criteria.
\end{abstract}

Keywords: transmission planning; island interconnections; security analysis; energy simulation; economic assessment

\section{Introduction}

A special characteristic of Greece is the large number of islands located in the Ionian Sea as well as the Aegean Sea. While most of the islands near the continental coast have been connected to the mainland grid via $150 \mathrm{kV}$ and medium voltage (MV) connections, there is a great number of autonomous and isolated island systems (either single islands or complexes of islands connected to each other via local MV subsea cable lines) that represent about $10 \%$ of the total electricity demand of Greece. The main problems related to the operation of non-interconnected islands (NIIs) are:

- $\quad$ Lack of alternative supply in case of autonomous power station (APS) fault

- High cost of energy produced by the APS compared to the continental system

- High variation of frequency due to low system inertia

- High variation of voltage due to low short-circuit power level

- Short margin of system stability

- $\quad$ Restricted penetration of RES

The interconnection of the NIIs has been a priority of the Greek state, as well as a research objective, for many years [1-6]. Recently, the isolated systems of northeastern 
Cycladic Islands (Syros, Paros, Mykonos, and Naxos) have been interconnected to the mainland system $[7,8]$, while the interconnection of Crete via $150 \mathrm{kV}$ HVAC (high voltage alternating current) and HVDC (high voltage direct current) interconnectors is in progress. Moreover, the integrated interconnection of the southwestern Cycladic Islands (Thira, Folegandros, Milos, and Serifos) has been decided to be implemented in the following years $[9,10]$. A very long and high depth of laying subsea cable lines introduces a wide range of challenges that need special studies, design, and technology [11-17]. For example, the Crete-Peloponnese double circuit interconnection, which consists of a 135-km-long subsea part and a $43-\mathrm{km}$ underground part on the Crete side, recently became the longest cable HVAC interconnection constructed in the world. The project also constitutes the deepest (1 km maximum depth) HV interconnection in the world using a three-core cable with cross-linked polyethylene (XLPE) insulation. In addition, significant innovations in the cable design (lighter and stronger) as well as in its laying have been applied [18-21]. Moreover, the operation of parallel HVAC and HVDC interconnectors in Crete needs a special control and protection strategy [22-25]. A current view of the power system of Greece (Hellenic Transmission System, HETS) is presented in Table 1 and depicted in Figure 1.

Table 1. Main characteristics of the interconnected power system of Greece (2020 data).

\begin{tabular}{cc} 
Total Annual Peak Load (MW) & 9547 \\
Annual Peak System Load-Losses are included (MW) & 8631 \\
Total Net Energy Demand (GWh) & 49,932 \\
Net System Load (GWh) & 44,403 \\
Total Net Installed Thermal Generation Capacity (MW) & 8314 \\
Total Net Installed Hydropower Generation Capacity (MW) & 3171 \\
RES Generation (MW) & 7341 \\
RES Generation (GWh) & 13,881 \\
\hline
\end{tabular}

The operation of autonomous thermal power plants that exist on islands as well as further local conventional generation development are restricted by environmental constraints, further enhanced by the European Commission (EC) emissions directives 2010/75/EE and 2015/2193/EE, applicable from 2020 onward. It is noted that the current variable generation cost of NIIs varies from 100 to over $500 \mathrm{EUR} / \mathrm{MWh}$ [26], while the weighted average market price is about $65 \mathrm{EUR} / \mathrm{MWh}$ (data from the first quarter of 2021). Moreover, the power supply of the NII consumers is set at the same price tariff per consumer category as that applying to the country's mainland, as part of the Services of General Interest (SGI). Additionally, the target model—the wholesale electricity market modelaims to gradually harmonize, through coupling, different national electricity markets, so that a unified EU electricity market can be established. These different electricity markets include the wholesale market of forward electricity products (renamed the energy financial market), the day-ahead market (DAM), the intraday market (IDM), and the balancing market (BM). The Hellenic Energy Exchange (HEnEx) has been established, and the IPTO carries the responsibility of managing the aforementioned markets and balancing the system in real time.

Furthermore, the new islands' interconnection will enable the development of new onshore and offshore RES capacity in the Aegean Sea area, considering the rich wind, solar, and geothermal potential on the islands [27-29]. 


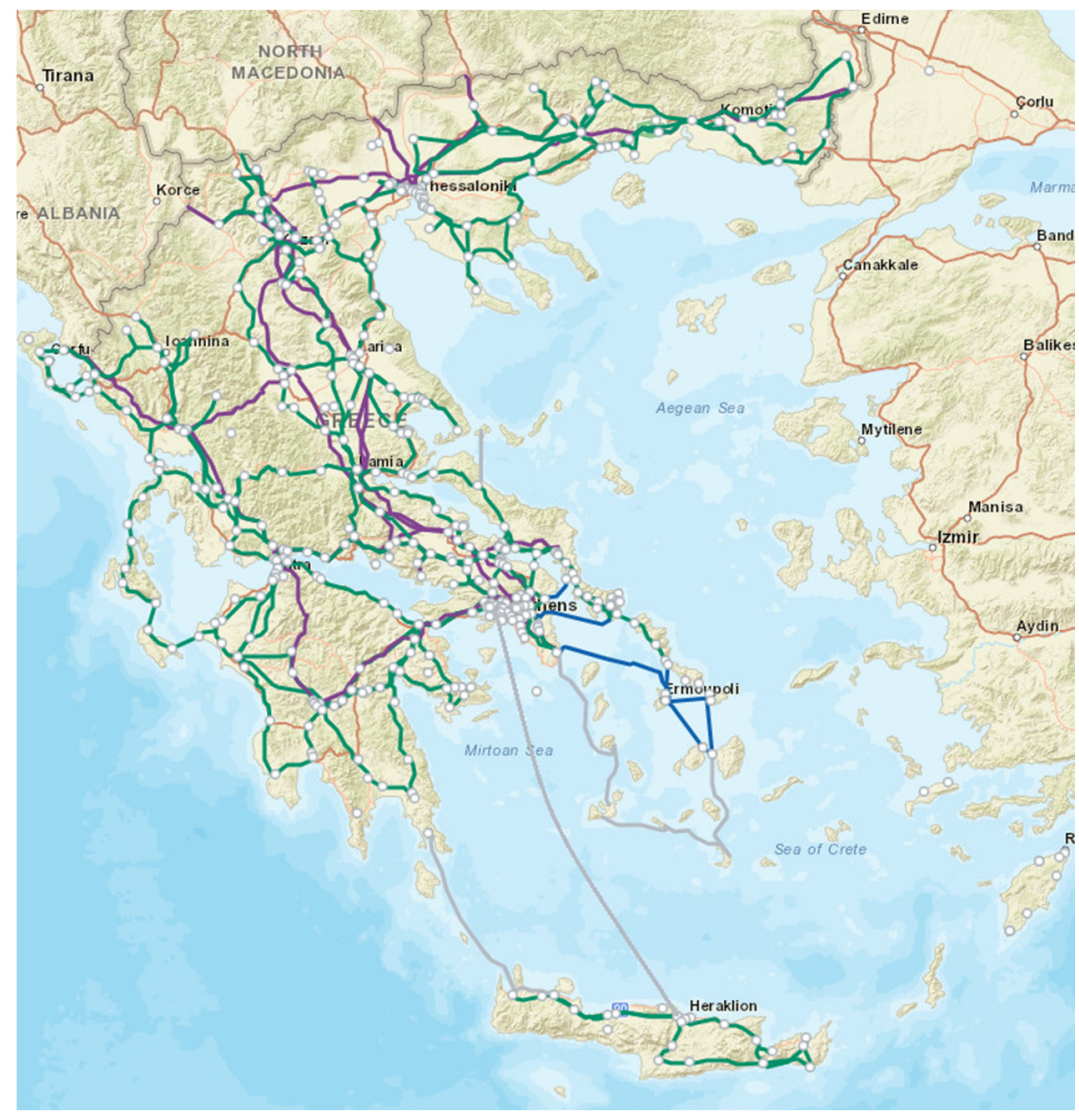

Figure 1. Map of the interconnected Hellenic Transmission System (HETS). Projects in progress are noted (grey lines), e.g., dual interconnection of Crete, a $150 \mathrm{kV} / \mathrm{AC}$ double circuit and a bipolar voltage source converter HVDC (VSC-HVDC), and southeastern Cycladic Islands (under planning/permitting licensing).

The Ministry of Energy and Climate Change, alongside the Regulatory Authority of Energy (RAE) in Greece, set up a joint task force (TF) with members from the Transmission System Operator (IPTO), Distribution Network Operator (HEDNO), and Natural Gas System Operator (DESFA), supported scientifically and technically by two project teams from the National Technical University of Athens (NTUA). The role of the TF was to examine the best and most economical option for electrification of the NII clusters as depicted in Figure 2; specifically, several scenarios were examined for autonomous operation based on natural gas or interconnection to the mainland grid. Finally, three deliverables were published $[9,10]$ :

The Rest of the Cycladic Islands, which are Serifos, Milos, Folegandros, and Thira, are promoted to be interconnected to the mainland via HVAC cables. It is noted that Syros, Paros, Naxos, Mykonos, Andros, and Tinos have already been interconnected in the past. The rest neighboring islands, specifically Kythnos, Sifnos, Anafi, Astypalea, Donousa, Amorgos, and Schinousa, will be interconnected via MV cables to the nearest island Substation.

i. The Dodecanese islands, which are the Kos-Kalymnos complex, Rodos, and Karpathos, are promoted to be interconnected to the mainland. Apart from Kastellorizo, which will remain an autonomous system, the rest of the neighboring islands, specifically Patmos, Arkoi, and Symi, will be interconnected via MV cables to the nearest island substation.

ii. The Northeast Aegean Sea islands, which are Skyros, Lemnos, Lesvos, Chios, and Samos, are promoted to be interconnected to the mainland via HVAC cables. Apart from 
Ag. Efstratios (Ai Stratis), which will remain an autonomous system, Ikaria and Agathonisi will be interconnected via MV cables to the Samos substation.

It is noted that the rest of the Aegean islands, which are mentioned above, are currently interconnected through 68 operating links in which more than 160 subsea MV cables of $1000 \mathrm{~km}$ in total length are installed.

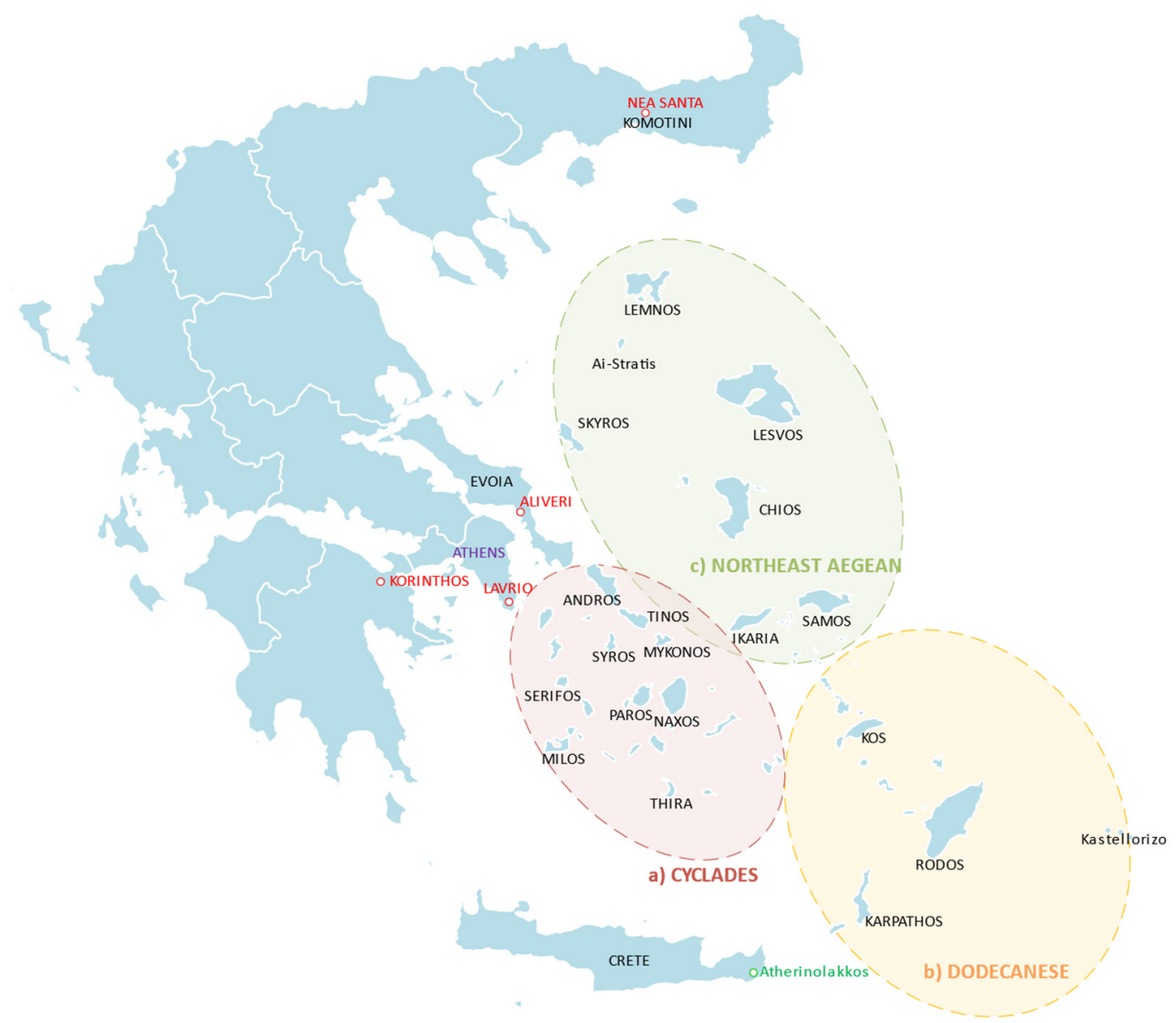

Figure 2. Map of island clusters: (a) Cycladic, (b) Dodecanese, and (c) Northeast Aegean Islands. Connection points are noted: Nea Santa, Aliveri, Lavrio, and Korinthos Extreme High Voltage Centers (EHVC) on the mainland as well as Atherinolakkos SS on Crete (under interconnection).

According to this conclusion, TSO and DNO conducted more detailed studies afterward in order to determine the necessary projects for the optimized implementation of the proposed interconnections. The preliminary studies at this stage were organized as follows:

- Project specification studies

- Finalization of the Master Plan regarding the islands' electrical connections

- Preliminary investigation of land planning of high voltage (HV) installations (e.g., substations and compensation devices) at the islands as well as the landing points of the submarine cables

- Investigation of subsea routes in the sea sections of the interconnections based on an in-office survey regarding the existing sea depths

- Investigation of overhead or alternatively underground routes over the land sections of the interconnected islands or the mainland system

- Technical specification studies

- Appropriate selection and dimensioning of submarine and underground cables and overhead lines $(\mathrm{OHL})$ in order to satisfy the necessary transmission capacity 
- Appropriate selection and dimensioning of HVDC interconnector equipment [30,31]

- Selection and dimensioning of an optimal compensation scheme of subseaunderground transmission lines (TLs) $[32,33]$

- Selection and dimensioning of dynamic compensation instruments, e.g., static VAR compensation (SVC) or static synchronous compensators (STATCOM)

- $\quad$ System-related studies

- Selection and sizing of reserves capacity

- Energy analysis with hourly operation simulation and detailed loss calculation

- Investigation of the possibility of developing new RES units on the interconnected islands

- Static security analysis of load flows (LFs) under conditions of permanent operation as well as under conditions of contingencies for characteristic snapshots throughout the examined period [34]

- Calculation of short-circuit currents

- Investigation of the needs of necessary conventional thermal power stations on the islands as well as the needs of emergency reserves that arise under conditions of serious contingencies on the interconnection circuits

- Scheduling of projects for their inclusion in the Ten-Year Network Development Plan (TYNDP) of the IPTO for implementation

Subsequently, two alternative scenarios were examined. The first scenario, which is based on pure HVAC 220/150 kV technology, investigated a vertical subsea loop corridor that starts in North Greece and ends interconnecting Crete, reinforced by a horizontal subsea branch from Central Greece to Lesvos. The second scenario investigated an HVDC interconnector from Peloponnese to Kos combined with HVAC $150 \mathrm{kV}$ subsea interconnection branches to the system as well as between the islands. The scope of this article is to inform on basic planning techno-economic variables. It does not present the results of the detailed contingency analyses $(\mathrm{N}-1)$ and short-circuit current calculations that have been conducted. Moreover, electromagnetic transient (EMT) analyses have not been performed at this preliminary stage of the study.

The general description of the interconnection diagrams and the basic technical characteristics of the equipment are presented in Section 2. Furthermore, the results of the static security analysis and the new RES development capacity are presented in Sections 3 and 4, respectively. Energy simulation results are the focus of Section 5, and the economic assessment is presented in Section 6. Qualitative benchmarking is performed in Section 7, while the Conclusions section is devoted to a discussion on the advantages and disadvantages of each solution.

\section{Interconnection Scenarios}

The design and study of alternative interconnection scenarios were based on meeting the following criteria:

- Network-centric approach to the island interconnections of all NIIs: The scope was to holistically deal with the interconnections of the Aegean Sea islands, in contrast to the separate study per cluster of islands (Cyclades, Crete, Dodecanese, and North Aegean).

- Creation of a unified grid of island interconnections: We attempted to interconnect the complexes apart from the HETS and between them.

- Reliable operating schemes: We aimed to ensure uninterrupted operation under conditions of critical contingencies.

- Ensuring scalability and interoperability: It is necessary to ensure the possibility of future extensions without requiring extensive projects and high costs.

- Economics and benefit of interconnections: The aim was to maintain the economy of the alternative scenarios, in comparison with the reference scenario, based on the 
proposals of the committee for examining the economics of the electrification method of the NIIs. The optimal exploitation of interconnection projects was sought.

- Capacity for the development of new RES units: The aim was to ensure significant margins for the development of new RES units on the interconnected islands.

Based on the above criteria, several alternative topologies were examined with a combination of different interconnection branches. According to the investigation conducted, the following conclusions emerged.

The clusters of the Northeast Aegean and Dodecanese islands should be coupled, especially in the case of a direct HVDC interconnection of HETS-Dodecanese. In this case, the operation of the HVDC interconnector will be based on an operating scheme corresponding with that selected for Crete, i.e., the active flow through the DC link will be controlled to maintain, within desired limits, the interface link to the AC link ending at the corresponding electrical node. In this way, the synchronization conditions will be based on the AC interconnection and the control under normal operating conditions of the HVDC interconnector will be voltage control on the HETS side and power control on the island side.

Furthermore, it is possible to electrify the Northeast Aegean and Dodecanese islands with only AC interconnections, i.e., without the implementation of the HVDC interconnectors. This, however, is possible only by adopting a voltage level higher than $150 \mathrm{kV} / \mathrm{AC}$ for the interconnection. Based on relevant investigations, the optimal voltage level for the implementation of this scenario is $220 \mathrm{kV}$.

The Cycladic and other Aegean island clusters should not be coupled at this stage. This was concluded because of the violations of operational limits in the Cyclades cluster, which may happen for various contingencies. In a later phase, with upgraded interconnections of Cyclades cluster, the scope of coupling the clusters could be reconsidered.

The Crete-Dodecanese interconnection is possible under certain conditions for specific topologies. This is a particularly difficult task in terms of implementation because of the high depth and existence of cracks. It also increases the complexity of the control scheme of the Attica-Crete interconnection. Conversely, it also leads to more efficient exploitation of the Attica-Crete interconnection.

Based on the above, two basic scenarios were selected and examined in detail:

- Interconnections Scenario A. This plan foresees a 220 and $150 \mathrm{kV}$ AC interconnection of the Northeast Aegean and Dodecanese Islands to the HETS through Nea Santa EHVC, Aliveri EHVC, and Atherinolakkos SS in Crete.

- Interconnections Scenario B. This plan foresees one (1) bipolar HVDC interconnector for the interconnection of the Dodecanese Islands directly to the HETS at the future Korinthos EHVC, along with $150 \mathrm{kV} / \mathrm{AC}$ interconnections of the Northeast Aegean Islands between islands and to the HETS.

Moreover, several new or reinforcements of MV interconnections are promoted:

- Ikaria and Agathonisi are promoted to be interconnected to the Samos MV grid.

- Patmos and Arkioi are promoted to be interconnected to the existing Kos-Kalymnos MV grid, which will be reinforced in order to securely supply all neighboring islands, e.g., Leros and Leipsoi.

- Simi is promoted to be interconnected to the Rodos MV grid.

The costs of these projects developed by HEDNO are defined as distribution investment costs. Finally, Agios Efstratios (Ai-Stratis) and Kastellorizo are not promoted to be interconnected. On the contrary, there are plans to develop smart hybrid technologies for their electrification transformation with a high penetration of RES, energy storage, and smart energy management (smart islands or green islands).

\subsection{Scenario A-HVAC Interconnection Topology}

This scenario, depicted in Figure 3, consists of the following new interconnection projects, substations (SS), and transmission lines (TLs): 


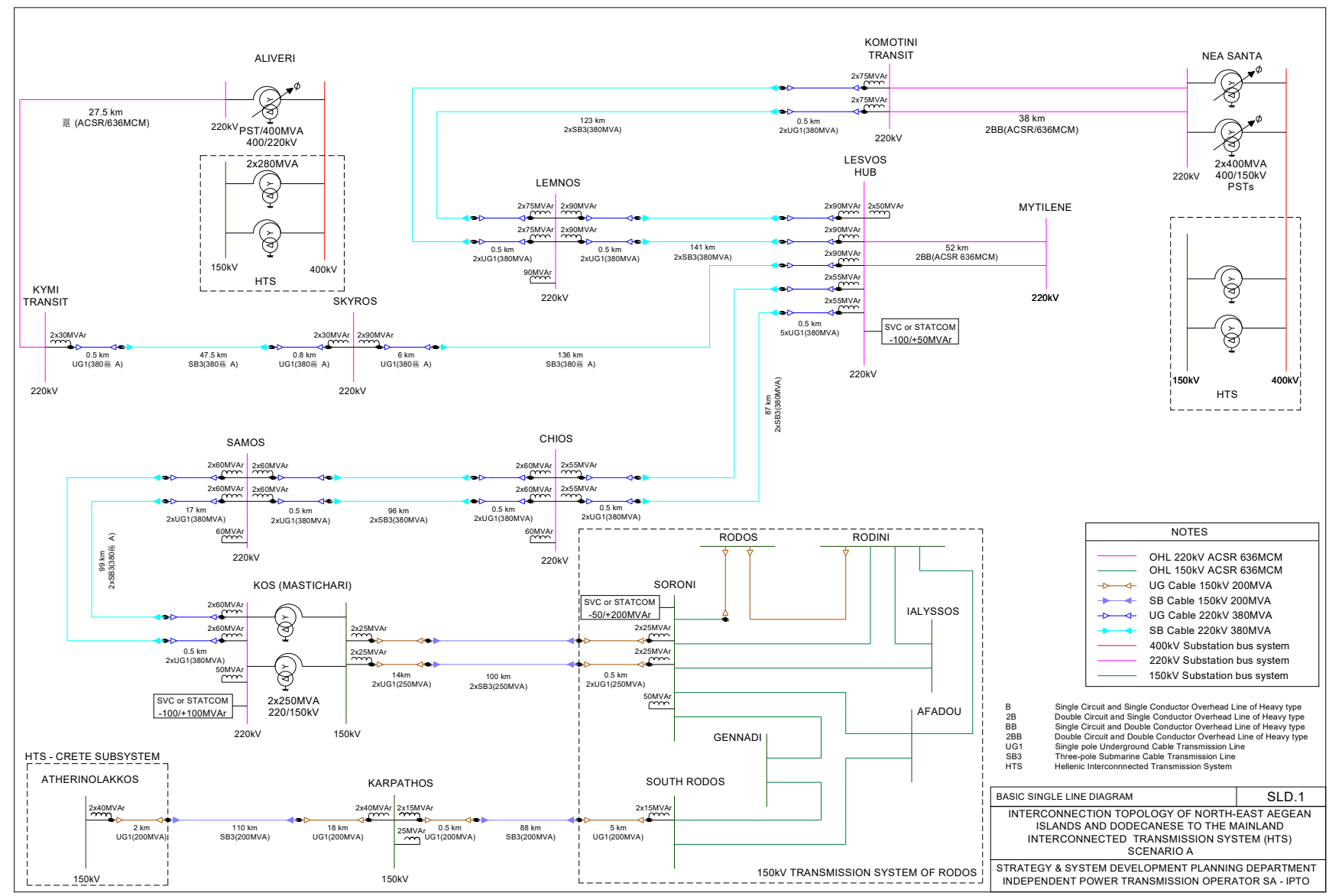

Figure 3. Single line diagram of Scenario A (HVAC interconnection topology).

- Nea Santa-Komotini (Transit)-Lemnos Interconnection. The $220 \mathrm{kV} / \mathrm{AC}$ interconnector is a double circuit with a nominal capacity of $2 \times 380 \mathrm{MVA}$. It consists of a terrestrial part (Nea Santa EHVC-Komotini) of two 45-km-long single-circuit OHLs and a subsea part (Komotini-Lemnos) of two 125-km-long 3-pole subsea cables. In addition, there is a need for two on-load phase-shifting power transformers of $400 / 220 \mathrm{kV}$ at Nea Santa EHVC.

- Lemnos-Lesvos HUB Interconnection. The $220 \mathrm{kV} / \mathrm{AC}$ interconnector is a double circuit with a nominal capacity of $2 \times 380$ MVA. It consists of a subsea part of two 140$\mathrm{km}$-long 3-pole subsea cables. There is a need for one (1) static VAR compensator system (SVC/STATCOM) that will be installed at the Lesvos HUB SS with a capacity of $-100 /+50$ MVAr.

- Aliveri-Skyros Interconnection. The $220 \mathrm{kV} / \mathrm{AC}$ interconnector is a single circuit with a nominal capacity of 380 MVA. It consists of a terrestrial part (Aliveri EHVC-Kymi Transit) of one 30-km-long single circuit OHL and a subsea part (Kymi TransitSkyros) of one 50-km-long 3-pole subsea cable. There is also a need for one on-load phase-shifting power transformer of $400 / 220 \mathrm{kV}$ at Aliveri EHVC.

- Skyros-Lesvos HUB Interconnection. The $220 \mathrm{kV} / \mathrm{AC}$ interconnector is a single circuit with a nominal capacity of 380 MVA. It consists of a subsea part (Skyros-Lesvos HUB) of one 140-km-long 3-pole subsea cable.

- Lesvos HUB-Chios Interconnection. The $220 \mathrm{kV} / \mathrm{AC}$ interconnector is a double circuit with a nominal capacity of $2 \times 380$ MVA. It consists of two 90-km-long 3-pole subsea cables.

- Chios-Samos Interconnection. The $220 \mathrm{kV} / \mathrm{AC}$ interconnector is a double circuit with a nominal capacity of $2 \times 380$ MVA. It consists of two 100-km-long 3-pole subsea cables. 
- Samos-Kos Interconnection. The $220 \mathrm{kV} / \mathrm{AC}$ interconnector is a double circuit with a nominal capacity of $2 \times 380$ MVA. It consists of two 100-km-long 3-pole subsea cables. There is a need for two power autotransformers of $220 / 150 \mathrm{kV}$ at Kos SS. In addition, there is a need for one (1) static VAR compensator system (SVC/STATCOM), which will be installed at the Kos SS, with a capacity of $-100 /+100$ MVAr.

- Kos-Rodos Interconnection. The $150 \mathrm{kV} / \mathrm{AC}$ interconnector is a double circuit with a nominal capacity of $2 \times 250$ MVA. It consists of two 100-km-long 3-pole subsea cables. There is a need for one (1) static VAR compensator system (SVC/STATCOM) that will be installed at the Rodos (Soroni SS) with a capacity of -50/+200 MVAr.

- Rodos (South Rodos)-Karpathos Interconnection. The $150 \mathrm{kV} / \mathrm{AC}$ interconnector is a single circuit with a nominal capacity of 200 MVA. It consists of one 90-km-long 3-pole subsea cable.

- Karpathos-Crete/Atherinolakkos Interconnection. The $150 \mathrm{kV} / \mathrm{AC}$ interconnector is a single circuit with a nominal capacity of 200 MVA. It consists of one 110-km-long 3-pole subsea cable.

- Six (6) new $220 \mathrm{kV}$ distribution substations (Indoor GIS type) in Lemnos, Lesvos, Skyros, Chios, Samos, and Kos, and one (1) new $150 \mathrm{kV}$ enclosed-type distribution substation in Karpathos. Note that numerous HV compensation reactors are located in all substations in order to compensate all cable lines.

\subsection{Scenario B-Mixed HVDC and HVAC Interconnection Topology}

This scenario, depicted in Figure 4, consists of the following new interconnection projects, substations (SS), and transmission lines (TLs):

- Nea Santa (HETS)-Komotini (Transit)-Lemnos Interconnection. The 150 kV / AC interconnector is a single circuit with a nominal capacity of 250 MVA. It consists of a terrestrial part (Nea Santa-Komotini) of one 45-km-long single circuit OHL and a subsea part (Komotini-Lemnos) of one 125-km-long 3-pole subsea cable. There is also a need for one on-load phase-shifting power transformer of 150/150 kV at Nea Santa EHVC.

- Lemnos-Lesvos HUB Interconnection. The $150 \mathrm{kV} / \mathrm{AC}$ interconnector is a single circuit with a nominal capacity of 250 MVA. It consists of a subsea part of one $140-\mathrm{km}-\mathrm{long}$ 3-pole subsea cable. There is a need for one (1) static VAR compensator system (SVC/STATCOM), which will be installed at the Lesvos HUB SS, with a capacity of $-50 /+100$ MVAr.

- Aliveri (HETS)-Skyros Interconnection. The $150 \mathrm{kV} / \mathrm{AC}$ interconnector is a single circuit with a nominal capacity of 250 MVA. It consists of a terrestrial part (Aliveri EHVC-Kymi Transit) of one 30-km-long single circuit OHL and a subsea part (Kymi Transit-Skyros) of one 50-km-long 3-pole subsea cable.

- Skyros-Lesvos HUB Interconnection. The $150 \mathrm{kV} / \mathrm{AC}$ interconnector is a single circuit with a nominal capacity of 250 MVA. It consists of the subsea part (Skyros-Lesvos HUB) of one 140-km-long 3-pole subsea cable.

- Lesvos HUB-Chios Interconnection. The $150 \mathrm{kV} / \mathrm{AC}$ interconnector is a single circuit with a nominal capacity of 250 MVA. It consists of one 90-km-long 3-pole subsea cable.

- Chios-Samos Interconnection. The $150 \mathrm{kV} / \mathrm{AC}$ interconnector is a single circuit with a nominal capacity of 250 MVA. It consists of one 100-km-long 3-pole subsea cable.

- Samos-Kos Interconnection. The $150 \mathrm{kV} / \mathrm{AC}$ interconnector is a single circuit with a nominal capacity of 250 MVA. It consists of one 100-km-long 3-pole subsea cable.

- Kos-Rodos Interconnection. The $150 \mathrm{kV} / \mathrm{AC}$ interconnector is a triple circuit with a nominal capacity of $3 \times 250$ MVA. It consists of three 100-km-long 3-pole subsea cables. There is a need for one (1) static VAR compensator system (SVC/STATCOM), which will be installed at Rodos (Soroni SS), with a capacity of $-100 /+100$ MVAr.

- Rodos (South Rodos)-Karpathos Interconnection. The $150 \mathrm{kV} / \mathrm{AC}$ interconnector is a single circuit with a nominal capacity of 200 MVA. It consists of one 90-km-long 3-pole subsea cable. 
- Korinthos (HETS)-Kos Interconnection. This is a bipolar HVDC interconnector with a $2 \times 450 \mathrm{MW}$ transmission capacity. It consists of two 400-km HVDC subsea cables as well as two $450 \mathrm{MW}$ terminal AC/DC converter stations at Korinthos and Kos.

- Six (6) new $150 \mathrm{kV}$ distribution substations (indoor GIS type) at Lemnos, Lesvos, Skyros, Chios, Samos, Kos, and Karpathos.

Note that numerous $\mathrm{HV}$ compensation reactors are located in all substations in order to compensate all cable lines.

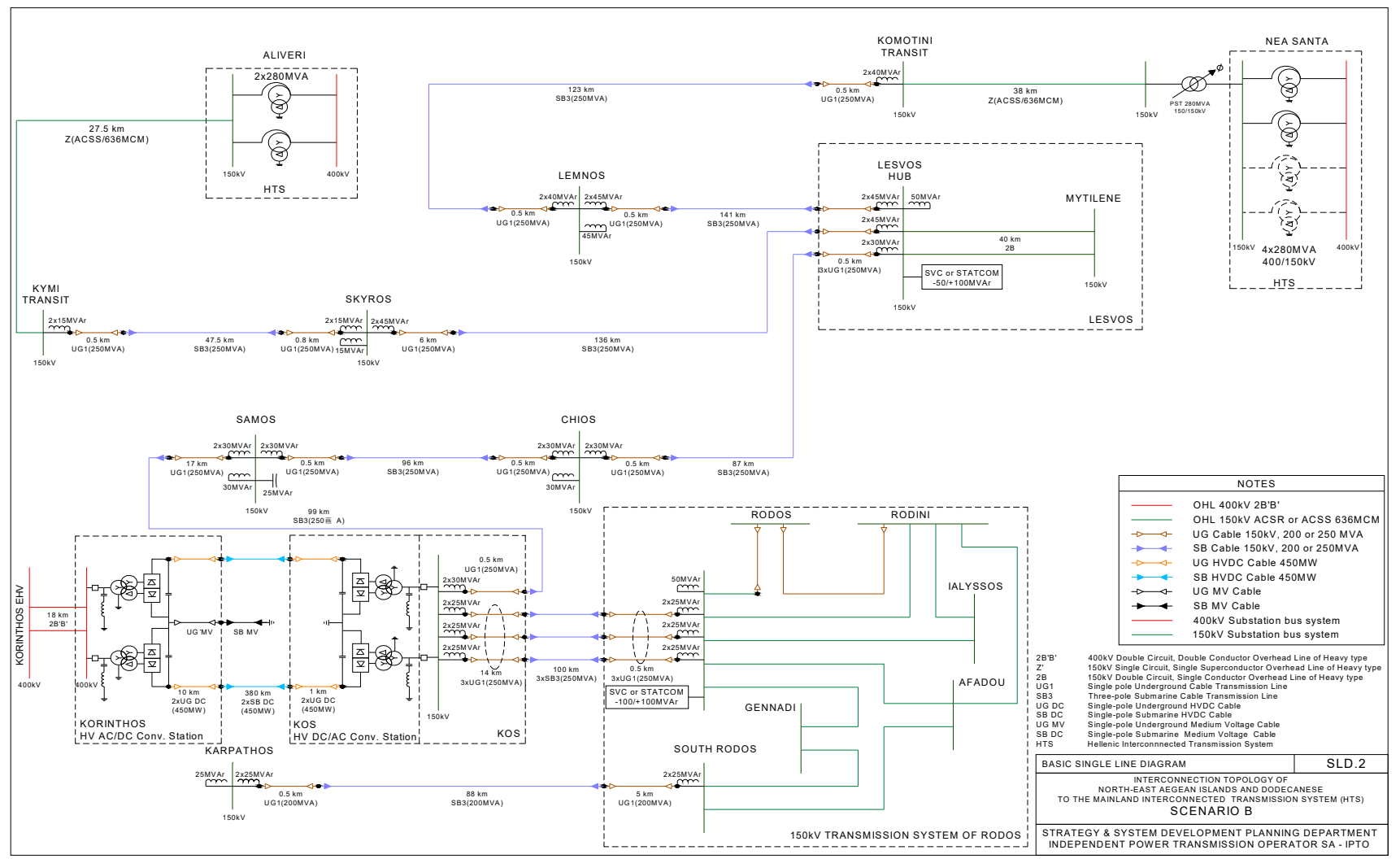

Figure 4. Single line diagram of Scenario B (mixed HVDC and HVAC interconnection topology).

\section{Static Security Analysis}

This section presents the results of the static analysis, which includes load flow analysis under normal and abnormal operating conditions. The criteria considered for the static safety analysis were:

- Satisfaction of thermal limits of the equipment

- Satisfaction of voltage limits, in accordance with the provisions of the HETS grid code, for normal and abnormal operating conditions during contingencies or errors in the system

- Satisfaction of $N-1$ reliability criterion. The system must be transiently capable of withstanding all critical contingencies without the risk of collapse (e.g., due to low voltages) or the risk of equipment damage (e.g., unacceptable overloads and surges).

- $\quad$ Overloads on AC cables were only accepted temporarily according to the emergency overload capacity of the cables based on their technical characteristics.

- $\quad$ To check the satisfaction of the $\mathrm{N}-1$ reliability criterion, all possible contingencies were examined, including either the loss of an interconnection circuit, the loss of one of the poles or cables of the DC interconnector, or the loss of a static (reactor) or dynamic (SVC/STATCOM) compensation device. For this purpose, technical aspects of the coordination between HVDC and HVAC links were also considered [20,22,25]. 
- Common-mode faults on parallel cables were not considered because of the separate routing assumption that was considered to be the case for the interconnections studied.

\subsection{Scenario A-HVAC Interconnection Topology}

For Scenario A (150-220 kV/AC), the following main conclusions emerged:

- Under normal operating conditions at peak-load conditions for the time horizon investigated in this study (until 2050), there are no violations of operational constraints, and the operation of the interconnections ensures the supply to the islands without the need for local production operation.

- Under abnormal operating conditions at peak load conditions for the time horizon investigated in this study (until 2050), which include simple loss ( $\mathrm{N}-1$ ) of interconnections, transient overloads of up to $25 \%$ for the year 2025 and up to $50 \%$ for the year 2050 are observed. To deal with these transient overloads, it is necessary to maintain local reserves set in operation after the outage in order to restore the loads within the permitted limits. The most critical contingencies are losses of the connections of Lesvos-Chios and Chios-Samos.

- Under minimum load conditions, the operation of the additional reactors in the substations of the interconnected SS is required in order to have no violations of operating limits in both normal and emergency operating conditions.

- The total required emergency reserves that need to be maintained on the interconnected islands is defined up to $220 \mathrm{MW}$, distributed as follows: $120 \mathrm{MW}$ at Rodos and $100 \mathrm{MW}$ at Chios or alternatively at Samos. With these reserves, the system can cope with all the expected contingencies.

\subsection{Scenario B-Mixed HVDC and HVAC Interconnection Topology}

Based on the results regarding Scenario B (mixed HVDC and HVAC interconnection topology) the following main conclusions emerged:

- Under normal operating conditions at maximum loads for the time horizon investigated in the study (until 2050), as well as in contingencies involving simple loss $(\mathrm{N}-1)$ of AC interconnections, no violations of operating limits are observed, and the operation of the interconnections ensures the supply to the islands without requiring the operation of local production.

- The most critical contingency is the loss of one of the poles or cables of the HVDC interconnector. During the first years of operation of the interconnections (2025-2035), with half-loading (450 MW) of the HVDC interconnector (before fault occurrence) in the transitional state just after the loss of the pole, there are transient overloads within acceptable limits on the cables of Samos-Chios, Lesvos-Chios, and SkyrosLesvos (higher transition overload at the Lesvos-Chios interconnection, up to 20\%) while with a $530 \mathrm{MW}$ loading (before a fault occurrence), there are no violations of operational limits during the transitional state. In the years after approximately 2035 (based on the predicted evolution of the loads), in order for the system to be able to cope with contingencies leading to pole loss of the HVDC interconnector, local reserve generation of about $70 \mathrm{MW}$ must be set into operation/dispatching (pre-contingency). Reserves should be located at least at Rodos; otherwise, load rejection of 70 MW may be executed.

- In case of minimum load conditions, additional reactors in the substations of Lemnos and Karpathos are required to be set in operation so that there are no violations of operation restrictions in either normal or emergency conditions.

- The total required emergency reserves that need to be maintained on the interconnected islands are approximately $130 \mathrm{MW}$, distributed as follows: $70 \mathrm{MW}$ at Rodos and $60 \mathrm{MW}$ at Chios or alternatively at Samos. If these reserves are available, the system can cope with all the expected contingencies, except in the case of the total loss of the HVDC interconnector. 


\subsection{New MV Islands Interconnections}

Beyond the HV interconnections of the abovementioned main islands, the rest of the small and isolated islands are studied to be interconnected or reinforced (for those that are already interconnected) via new submarine MV cable lines. Therefore, it is noted that:

- Ikaria and Agathonisi are promoted to be interconnected to Samos.

- Patmos and Arkoi are promoted to be connected to the Kos-Kalymnos MV complex. It is noted that numerous islands neighboring Kos and Kalymnos are already interconnected, e.g., Leipsoi, Leros, Pserimos, Nisiros, and Telos. In addition, additional MV lines are proposed for the reinforcement of the inter-island MV grid.

- Simi is promoted to be connected to the Rodos complex via MV subsea cable lines, while Chalki is already connected.

- Kasos is already interconnected to the Karpathos complex.

Moreover, it is mentioned that the new MV interconnection projects are the same for both Scenarios A and B. Of course, the current thermal power plants of the above deisolated islands will be withdrawn.

\section{RES Development Capacity}

The assessment of the development of new RES capacity on the interconnected islands was based on the following methodology:

- In conditions of minimum load, RES power is gradually increased in all interconnected islands. In the examined scenario, the total load on the interconnected islands amounts to approximately $115 \mathrm{MW}$.

- The new RES development capacity is distributed on all islands according to each island's geographic area $\left(\mathrm{km}^{2}\right)$, as well as according to the average annual wind speeds.

- The criterion for finding the limits of maximum absorption capacity per island is the secure operation of the overall interconnected network in normal $(\mathrm{N})$ and emergency $(\mathrm{N}-1)$ operating conditions.

- The violation of operating limits leads to a redistribution of the power of RES units distributed to the islands (with the result that the final distribution is not necessarily based on the initial percentages) in order to maximize the total capacity of new RES plants to be developed in the Northeast Aegean and Dodecanese Islands.

- The penetration limit resulting from the above methodology corresponds to simultaneous generation. Considering a simultaneity rate of $90 \%$, the total acceptable installed capacity of new RES units per island is obtained.

Table 2 presents the results grouped by scenario for the clusters of the Northeast Aegean and Dodecanes Islands. Based on this clustering, it is possible to develop more RES units on some islands compared with others belonging to the same cluster.

Table 2. New RES development capacity per island cluster after interconnections.

\begin{tabular}{ccc}
\hline Island & $\begin{array}{c}\text { Scenario A } \\
\text { HVAC Topology }\end{array}$ & $\begin{array}{c}\text { Scenario B } \\
\text { Mixed HVDC \& HVAC Topology }\end{array}$ \\
\hline $\begin{array}{c}\text { Lemnos } \\
\text { Lesvos } \\
\text { Chios } \\
\text { Samos }\end{array}$ & $480 \mathrm{MW}$ & $360 \mathrm{MW}$ \\
\hline Skyros & $130 \mathrm{MW}$ & $100 \mathrm{MW}$ \\
\hline $\begin{array}{c}\text { Kos } \\
\text { Rodos } \\
\text { Karpathos }\end{array}$ & $390 \mathrm{MW}$ & $570 \mathrm{MW}$ \\
\hline Total & $1000 \mathrm{MW}$ & $1030 \mathrm{MW}$ \\
\hline
\end{tabular}




\section{Energy Simulation}

For the calculation of the energy supplied by HETS for the electrification of the interconnected islands, an hourly energy simulation of the operation of all the islands was performed based on each interconnection scenario. In this context, the following information was considered:

- Time series of the average demand for electricity of the islands for all the years of the examined period (indicated as $P_{\text {Load, }, k}^{h}$ for island $k$ at hour $h$ ). These time series are based on reports considering the predicted increase in demand for the following years. Table 3 presents the maximum demand forecasting per cluster for the 2025-2050 period.

- $\quad$ Time series of the average hourly generation of existing RES units (indicated as $P_{P V, k}^{h}$ and $P_{W, k}^{h}$ for PV and wind generation, respectively)

- Technical and economic data of conventional thermal generation units considered to be maintained on the islands of Rodos, Chios, and/or Samos as emergency reserves

- Characteristics of power transmission and losses of the interconnections. Regarding the power losses for a cable connecting node $k$ and node $n P_{l o s s}^{k n}$, a polynomial approximation was used following Equation (1):

$$
P_{l o s s}^{k n}=a \cdot P_{k n}^{2}+b \cdot P_{k n}+c
$$

Table 3. Peak (maximum) demand forecasting per cluster for the period of 2025-2050.

\begin{tabular}{|c|c|c|c|c|c|c|}
\hline \multirow{2}{*}{ Cluster Peak Demand (MW) } & \multicolumn{6}{|c|}{ Year } \\
\hline & 2025 & 2030 & 2035 & 2040 & 2045 & 2050 \\
\hline $\begin{array}{c}\text { Dodecanese Islands } \\
\text { Rodos, Karpathos, Kos-Kalymnos complex }\end{array}$ & 389 & 424 & 454 & 476 & 498 & 520 \\
\hline $\begin{array}{l}\text { N.E. Aegean Islands } \\
\text { Lemnos, Lesvos, Chios, Samos-Ikaria complex, Skyros }\end{array}$ & 190 & 203 & 214 & 224 & 233 & 243 \\
\hline
\end{tabular}

Notes: Ai-Stratis and Kastellorizo are not promoted to be interconnected and are not included, while solutions will be examined for the transition to smart/green islands. The clusters include all neighboring islands, which are either connected or are going to be interconnected via subsea MV lines.

At the connection points to the HETS, the system was modeled as an equivalent generation unit with a capacity equal to the capacity of the transmission cables and an energy cost equal to the anticipated SMP. A DC optimal power flow (OPF) approach was adopted to dispatch power to the interconnections and local generation units [35].

According to the DC power flow, the power transfer between node $k$ and node $n$ of the system was calculated by Equation (2):

$$
P_{k n}=b_{k n} \cdot\left(\delta_{k}-\delta_{n}\right)
$$

in which $b_{k n}$ is the susceptance of the line(s) between bus $k$ and bus $n$, and $\delta_{k}$ and $\delta_{n}$ are the voltage angles.

The objective function of the optimization problem was defined by Equation (3):

$$
\min \sum_{h=1}^{24} \sum_{i=1}^{N G E N}\left(C\left(P_{\text {gen }, i}^{h}\right)+V O L L \cdot P_{\text {Load }, \text { curt }}^{h}\right)+C_{\text {penalty }}
$$

where $C\left(P_{g e n, i}^{h}\right)$ is the cost of generation of active power $P_{g e n, i}^{h}$ by unit $i$ at hour $h$, NGEN is the number of generation units and points of interconnection to the HETS, $C_{\text {penalty }}$ is the penalty cost incurred by wind curtailments,

VOLL is the value of the lost load, and $P_{\text {Load, curt }}^{h}$ is the load curtailment at hour $h$

The objective function was minimized subject to the following constraints: 
- $\quad$ System power balance constraints. Total generation from local units, interconnection points, and RES shall be equal to the total load of the system and the losses of the interconnections cables:

$$
\sum_{i=1}^{N G E N} P_{g e n, i}^{h}+P_{W}^{h}+P_{P V}^{h}=P_{\text {Load }}^{h}+P_{\text {loss }}^{h}-P_{\text {Load }, \text { curt }}^{h}
$$

- $\quad$ Power balance constraint at each node. The net power injected at node $k$ by all cables connected to this node, local generating units, and RES, shall be equal to the load demand of node $k$ (subtracting any load curtailment at this node) and the losses attributed to node $k\left(P_{\text {loss }, k}^{h}\right)$ as expressed in Equation (5):

$$
\sum_{i=1}^{N G E N_{k}} P_{g e n, i, k}^{h}+\sum_{n \in A(k)} P_{k n}^{h}+P_{W, k}^{h}+P_{P V, k}^{h}=P_{\text {Load }, k}^{h}+P_{\text {loss }, k}^{h}-P_{\text {Load }, \text { curt }, k}^{h}
$$

- $\quad$ Cable capacity constraints. $\left(\left|P_{k n}\right| \leq P_{k n}^{\max }\right)$

- Angle constraints. $\left(\delta_{k}<90^{\circ}\right)$

- Generation unit constraints. This includes the technical minimum and maximum constraints, as well as ramp-up and ramp-down constraints and minimum up and down time.

Applying the mentioned methodology of hourly energy simulation, the calculated outputs are shown in Table 4. Based on the results, we observed:

- For Scenario A (HVAC Topology), most of the demand of the islands is covered through the interconnection with the HETS in the north (Nea Santa) at a rate of about $40 \%$, while the energy supplied by Aliveri EHVC (central HETS) and Atherinolakkos SS in Crete is $20 \%$ and $21 \%$ of the demand of the islands, respectively.

- As expected, in Scenario B (Mixed HVDC and HVAC Topology), most of the island demand is covered through the DC link at a rate of about $63 \%$, while the energy supplied to the islands via HETS from the AC interconnections with Nea Santa EHVC and Aliveri EHVC is $10 \%$ and $12 \%$ of the demand of the islands, respectively.

- The weighted average energy loss rates on the interconnected energy is between $4.8 \%$ and $5.1 \%$ for Scenario A and between $6.2 \%$ and $6.9 \%$ for Scenario B throughout the period considered.

\begin{tabular}{|c|c|c|c|c|c|c|}
\hline \multirow{2}{*}{ Basic Energy Characteristics } & \multicolumn{6}{|c|}{ Year } \\
\hline & 2025 & 2030 & 2035 & 2040 & 2045 & 2050 \\
\hline Net demand at S/S level (GWh) & 2120.9 & 2223.2 & 2330.1 & 2441.7 & 2555.7 & 2677.0 \\
\hline Thermal generation on islands (GWh) & 0.0 & 0.0 & 0.0 & 0.0 & 0.0 & 0.0 \\
\hline Rodos local generation & 0.0 & 0.0 & 0.0 & 0.0 & 0.0 & 0.0 \\
\hline Lesvos local generation & 0.0 & 0.0 & 0.0 & 0.0 & 0.0 & 0.0 \\
\hline RES generation (GWh) & 444.4 & 465.0 & 489.6 & 510.7 & 533.2 & 560.7 \\
\hline Wind generation & 288.3 & 303.7 & 318.2 & 333.7 & 349.7 & 366.3 \\
\hline Rest RES & 156.1 & 161.3 & 171.4 & 177.0 & 183.5 & 194.4 \\
\hline \multicolumn{7}{|c|}{ Scenario A (HVAC interconnection topology) } \\
\hline Energy supplied from HETS by HVAC interconnectors (GWh) & 1761.1 & 1847.4 & 1934.6 & 2030.8 & 2128.3 & 2228.5 \\
\hline HVAC interconnector from Nea Santa EHVC & 868.5 & 910.7 & 953.4 & 1001.5 & 1048.8 & 1098.9 \\
\hline HVAC interconnector from Aliveri EHVC & 421.1 & 446.1 & 470.6 & 498.5 & 524.9 & 553.9 \\
\hline HVAC interconnector from Atherinolakkos SS & 471.5 & 490.7 & 510.6 & 530.8 & 554.7 & 575.7 \\
\hline Transmission losses (GWh) & 84.5 & 89.2 & 94.0 & 99.8 & 105.8 & 112.2 \\
\hline Average losses factor & $4.80 \%$ & $4.83 \%$ & $4.86 \%$ & $4.91 \%$ & $4.97 \%$ & $5.03 \%$ \\
\hline \multicolumn{7}{|c|}{ Scenario B (Mixed HVDC and HVAC topology) } \\
\hline Energy supplied from HETS by HVAC interconnectors (GWh) & 1800.9 & 1885.3 & 1970.5 & 2064.2 & 2256.6 & 2256.6 \\
\hline HVDC interconnector from Korinthos EHVC & 1341.1 & 1406.3 & 1470.4 & 1542.0 & 1615.4 & 1688.1 \\
\hline HVAC interconnector from Nea Santa EHVC & 204.0 & 213.0 & 222.1 & 231.7 & 241.0 & 251.7 \\
\hline HVAC interconnector from Aliveri EHVC & 254.8 & 266.0 & 278.0 & 290.6 & 302.8 & 316.8 \\
\hline Transmission losses (GWh) & 124.4 & 127.1 & 130.0 & 133.2 & 136.6 & 140.3 \\
\hline Average losses factor & $6.91 \%$ & $6.74 \%$ & $6.59 \%$ & $6.45 \%$ & $6.33 \%$ & $6.22 \%$ \\
\hline
\end{tabular}

Table 4. Energy simulation results. 


\section{Economic Assessment}

This section presents the results of the cost analysis of the solution as well as the preliminary economic evaluation (prefeasibility) of the interconnection scheme with a combination of HVDC and $150 \mathrm{kV} / \mathrm{AC}$ interconnectors. It should be noted that cost estimation of interconnection projects is usually difficult because of the special specifications and uniqueness of each project, specifically the HVDC projects [36].

In particular, the following items were calculated:

- Total investment cost of the necessary new transmission and distribution projects (CAPEX) for the implementation of the new offshore grid

- Net present value of the total cost of electricity (Energy Cost, NPV) of the interconnected islands for the 2025-2050 period considered

- Levelized cost of energy (LCOE).

The calculation of the NPV assumed a duration of investment payback of 35 years, a discount rate of $8 \%$, system marginal price (SMP) of $74.5 \mathrm{EUR} / \mathrm{MWh}$, and a 25 -year period for the calculation of the total cost of electricity.

Based on the above assumptions, Table 5 presents the results of the economic computations for scenarios A and B.

Table 5. Economic analysis.

\begin{tabular}{|c|c|c|c|c|c|c|}
\hline \multicolumn{7}{|c|}{ a. Results for Scenario A (HVAC Interconnection Topology) } \\
\hline \multirow{2}{*}{ Economic Characteristic } & \multicolumn{6}{|c|}{ Year } \\
\hline & 2025 & 2030 & 2035 & 2040 & 2045 & 2050 \\
\hline Transmission Total Investment Cost, CAPEX (M EUR) & \multicolumn{6}{|c|}{2304.343} \\
\hline Transm. Annual Capital Cost (M EUR) & 197.720 & 197.720 & 197.720 & 197.720 & 197.720 & 197.720 \\
\hline Transm. Annual Oper. \& Maint. Cost, OPEX (M EUR) & 23.043 & 23.043 & 23.043 & 23.043 & 23.043 & 23.043 \\
\hline Distribution Total Investment Cost, CAPEX (M EUR) & \multicolumn{6}{|c|}{49.503} \\
\hline Distr. Annual Capital Cost (M EUR) & 4.248 & 4.248 & 4.248 & 4.248 & 4.248 & 4.248 \\
\hline Total Annual Cost Transmission \& Distribution & 240.378 & 240.378 & 240.378 & 240.378 & 240.378 & 240.378 \\
\hline Annual Cost of Reserves (M EUR) & 15.4 & 15.4 & 15.4 & 15.4 & 15.4 & 15.4 \\
\hline System Marginal Price (EUR/MWh) & \multicolumn{6}{|c|}{74.5} \\
\hline Cost of Energy Generated by System (M EUR) & 131.199 & 137.633 & 144.129 & 151.296 & 158.560 & 166.024 \\
\hline Total Cost of Supplied Energy (EUR/MWh) & 371.577 & 378.012 & 384.507 & 391.674 & 398.938 & 406.403 \\
\hline NPV of Scenario A (M EUR) & \multicolumn{6}{|c|}{4470.832} \\
\hline LCOE of Scenario A (EUR/MWh) & \multicolumn{6}{|c|}{210.35} \\
\hline \multicolumn{7}{|c|}{ b. Results for Scenario B (Mixed HVDC and HVAC Topology) } \\
\hline \multirow[b]{2}{*}{ Economic Characteristic } & \multicolumn{6}{|c|}{ Year } \\
\hline & 2025 & 2030 & 2035 & 2040 & 2045 & 2050 \\
\hline Transmission Total Investment Cost, CAPEX (M EUR) & \multicolumn{6}{|c|}{2342.142} \\
\hline Transm. Annual Capital Cost (M EUR) & 200.963 & 200.963 & 200.963 & 200.963 & 200.963 & 200.963 \\
\hline Transm. Annual Oper. \& Maint. Cost, OPEX (M EUR) & 23.421 & 23.421 & 23.421 & 23.421 & 23.421 & 23.421 \\
\hline Distribution Total Investment Cost, CAPEX (M EUR) & \multicolumn{6}{|c|}{49.503} \\
\hline Distr. Annual Capital Cost, (M EUR) & 4.248 & 4.248 & 4.248 & 4.248 & 4.248 & 4.248 \\
\hline Total Annual Cost Transmission \& Distribution & 238.804 & 238.804 & 238.804 & 238.804 & 238.804 & 238.804 \\
\hline Annual Cost of Reserves (M EUR) & 10.2 & 10.2 & 10.2 & 10.2 & 10.2 & 10.2 \\
\hline System Marginal Price (EUR/MWh) & \multicolumn{6}{|c|}{74.5} \\
\hline Cost of Energy Generated by System (M EUR) & 134.168 & 134.168 & 134.168 & 134.168 & 134.168 & 134.168 \\
\hline Total Cost of Supplied Energy (EUR/MWh) & 372.971 & 372.971 & 372.971 & 372.971 & 134.168 & 134.168 \\
\hline NPV of Scenario B (M EUR) & \multicolumn{6}{|c|}{4483.958} \\
\hline LCOE of Scenario B (EUR/MWh) & \multicolumn{6}{|c|}{210.96} \\
\hline
\end{tabular}

In conclusion, based on the results, the following could be ascertained:

- The total cost of the interconnection projects for the electricity supply of the islands (CAPEX) is about EUR 2.3 B for the investigated scenarios. 
- The levelized energy cost (LCOE) is about 211 EUR/MWh for scenarios considered, considering that the LCOE value of the NIIs is currently up to $500 \mathrm{EUR} / \mathrm{MWh}$.

\section{Discussion: Qualitative Benchmarking of the Scenarios}

The main advantages of Scenario A, with $150 \mathrm{kV} / \mathrm{AC}$ and $220 \mathrm{kV} / \mathrm{AC}$ interconnectors, are summarized as follows:

- Development of a "meshed" offshore grid with four connection points to the HETS (one of them with Crete)

- Capacity for development of new RES units on the interconnected islands

- Reduced transmission losses

- However, this interconnection scheme has the following disadvantages:

- Requirement to maintain higher emergency power reserves

- Requirement for new equipment specifications for the $220 \mathrm{kV}$ level (currently not operated in Greece)

- Long distance from the load center

- $\quad$ First application of $220 \mathrm{kV}$ voltage equipment for the HETS

- Asset management issues of new equipment that arise with the introduction of a new voltage level

- Complexity of the control operation strategy of the HVDC interconnection of AtticaCrete because of the connection of Crete with the Dodecanese Islands

The main advantages of interconnection scenario B, with a combination of HVDC and $150 \mathrm{kV} /$ AC links, are summarized as follows:

- Direct power supply corridor of the load center from HETS

- Capacity for the development of new RES units on the interconnected islands

- Technical and engineering readiness regarding equipment specifications

- However, this interconnection scheme has the following disadvantages:

- Great dependence of the whole project of the interconnection of the Northeast Aegean and Dodecanes Islands from the implementation of the Korinthos-Kos HVDC project

- Increased transmission losses

Moreover, new trends on offshore RES connection can be enabled with the HVDC technology $[37,38]$ jointly with HVAC cutting-edge equipment.

Evaluating all the study findings, especially the disadvantages of Scenario A (220 kV/ $\mathrm{AC}$ interconnectors) regarding the requirement to maintain more reserves, the long distance of the connections from the load center, and the complexity in the control scheme of the Attica-Crete HVDC interconnection due to the connection with the Dodecanese Islands, Scenario B (HVDC interconnection of Korinthos-Kos and 150 kV/AC interconnections of the other islands with each other and with the HETS at N. Santa and Aliveri EHVCs) was adopted for implementation by the TSO [39], while the new MV interconnections and reinforcements will be planned by the DNO. Figure 5 presents the system development plan of island HV interconnections (MV interconnections are not depicted). The new interconnections will enable the deisolation of islands and energy transition to reliable, resilient, and economic power delivery. Moreover, the rich RES potential will be utilized where possible. 


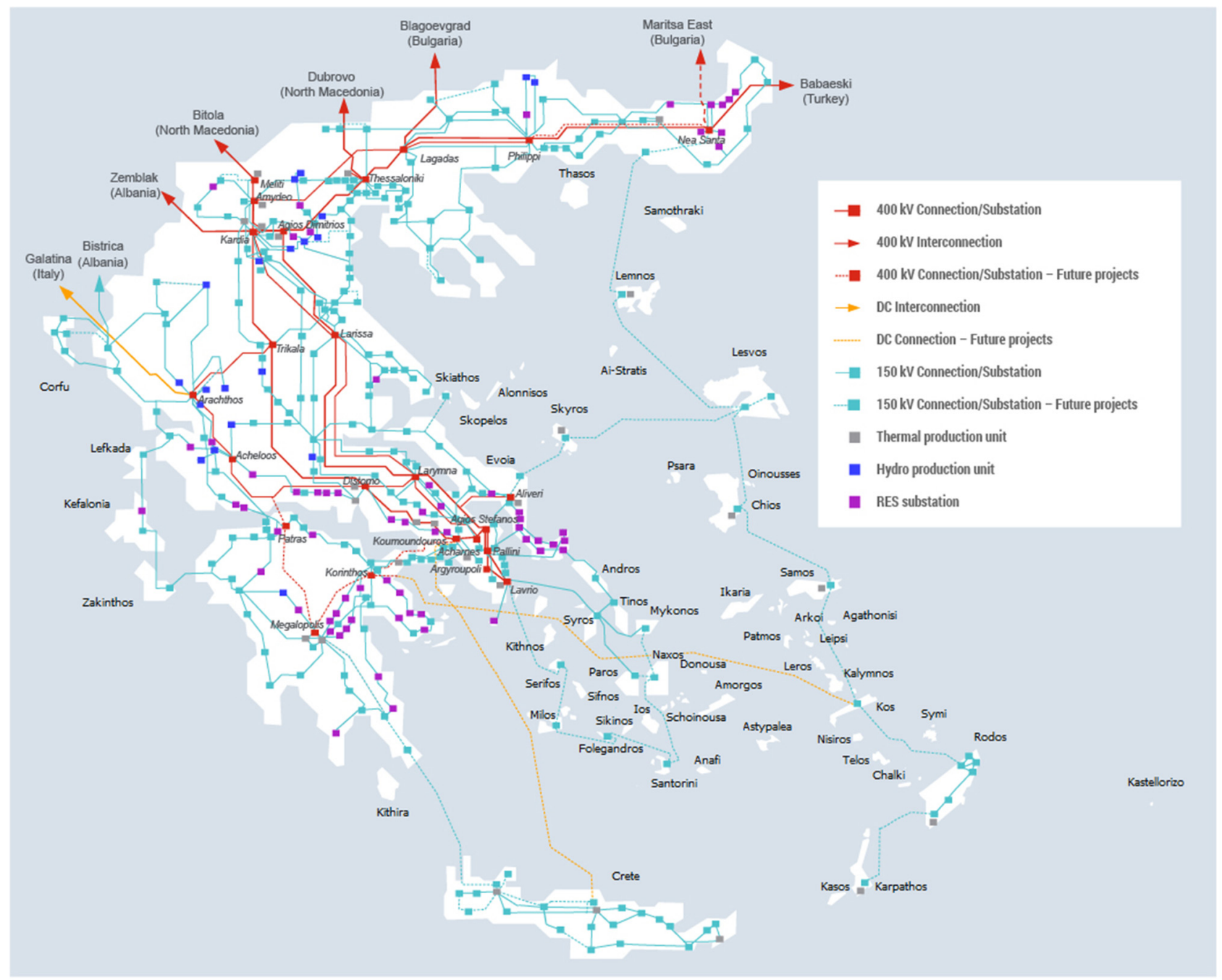

Figure 5. System development planning of the Dodecanese and Northeast Aegean Islands interconnection in the case of scenario B. The rest of the Cycladic Islands and Crete interconnections are currently projects in the implementation process.

\section{Conclusions}

This article presents a holistic approach to the Aegean archipelago NII interconnections to the continental power grid of Greece. During the network-centric investigation that was carried out, numerous network topologies and cutting-edge transmission technologies were examined in order to promote an optimal economic, secure, and resilient network architecture. Finally, the authors extensively studied and compared two interconnection scenarios: Scenario A, based on pure HVAC (220 kV and $150 \mathrm{kV})$ technology, and Scenario $\mathrm{B}$, based on a bipolar HVDC interconnector from the mainland to Kos island and $150 \mathrm{kV} / \mathrm{AC}$ subsea cable transmission lines. The main conclusions of the investigation initially conducted in the present study can be summarized as follows:

- The clusters of the Northeast Aegean and Dodecanese Islands should be interconnected, while at this stage it is not appropriate to interconnect them with the Cycladic Islands.

- It is possible to interconnect the Northeast Aegean and Dodecanese Islands exclusively with AC interconnectors, but only with the adoption of voltage levels higher than $150 \mathrm{kV}$.

- The Crete-Dodecanese interconnection is possible under certain conditions for specific topologies.

- Based on the investigation, two main scenarios were selected and examined in depth: 
- Scenario A, with interconnections at AC voltage levels of $220 \mathrm{kV}$ and $150 \mathrm{kV}$ for the interconnection of the Dodecanese and Northeast Aegean Islands to the HETS via the Nea Santa EHVC, Aliveri EHVC, and Atherinolakkos SS in Crete.

- Scenario B, with a bipolar HVDC interconnection of the Dodecanese Islands with HETS at Korinthos EHVC and $150 \mathrm{kV} / \mathrm{AC}$ connections for the Northeast Aegean Islands.

According to the static security analysis of the abovementioned scenarios, the secure electricity supply to the islands is ensured in normal and emergency operating conditions. For this purpose, it is required to maintain in cold reserve status some local reserves on the islands of Rodos and Chios or Samos of about 130 MW for Scenario B (HVDC and $150 \mathrm{kV} / \mathrm{AC}$ ) and of about $220 \mathrm{MW}$ for Scenario A (150-220 kV/ AC).

From an economic point of view, the scenarios yield equivalent results, with the total investment/capital cost (CAPEX) of the interconnection projects for the electricity supply of the islands amounting to approximately EUR 2.3 B and the levelized energy cost (LCOE) to approximately $211 \mathrm{EUR} / \mathrm{MWh}$. In addition, the scenarios are practically equivalent in terms of the capacity for developing new RES units of about 1000 MW in the interconnected islands.

Author Contributions: Conceptualization, M.E.K., C.N.P. and S.P.E.; methodology, M.E.K., C.N.P., S.P.E. and E.M.V.; software, C.N.P. and E.M.V.; validation, M.E.K., S.P.E. and E.A.L.; formal analysis, C.N.P., S.P.E., M.A.T., J.C.M., E.M.V. and N.G.S.; investigation, M.E.K., C.N.P. and S.P.E.; resources, M.E.K. and E.A.L.; data curation, M.E.K., S.P.E., M.A.T. and E.A.L.; writing-original draft preparation, M.E.K. and C.N.P.; writing-review and editing, M.E.K., C.N.P., J.C.M. and N.G.S.; visualization, C.N.P.; supervision, M.E.K., S.P.E. and E.A.L.; project administration, M.E.K., S.P.E. and E.A.L. All authors have read and agreed to the published version of the manuscript.

Funding: This research received no external funding.

Acknowledgments: The authors express their acknowledgments to the Transmission New Projects Department of IPTO for providing data on substations, HVDC converter stations, underground and submarine cables, and overhead transmission lines as well as to the Research, Technology and Development Department of IPTO for support. The authors would also like to express their appreciation to the anonymous reviewers for their in-depth review of the manuscript and their valuable comments for quality improvement of the article.

Conflicts of Interest: The authors declare no conflict of interest.

Disclaimer: This paper is a technical case study. The opinions expressed in this publication are those of the authors. They do not purport to reflect the opinions or views of IPTO and HEDNO.

\section{References}

1. Papadopoulos, M.; Papathanasiou, S.; Tsili, M.; Karamanou, E. Strategic Study for the Interconnection of Autonomous Island Power Systems-Preliminary Studies'; Technical Report; NTUA: Athens, Greece, 2007. (In Greek)

2. Papadopoulos, M.; Boulaxis, N.; Tsili, M.; Papathanassiou, S. Increased wind energy exploitation via interconnection of Aegean island to the mainland grid. In Proceedings of the 19th International Conference on Electricity Distribution (CIRED), Vienna, Austria, 21-24 May 2007; pp. 1-4.

3. Papadopoulos, M.; Papathanasiou, S.; Karamanou, E. Update of the Strategic Study for the Islands Interconnection to the System; Technical Report; NTUA: Athens, Greece, 2008. (In Greek)

4. Karamanou, E.; Papathanassiou, S.; Papadopoulos, M. Planning the interconnection of islands to the mainland grid via submarine cables. In Proceedings of the 2008 IET MedPower Conference, Thessaloniki, Greece, 2-5 November 2008.

5. HTSO/DESMIE. Study of the Aegean Sea Islands Inter-Connection to the System-Phase A: General Planning; Technical Report; Regulatory Authority for Energy (RAE): Athens, Greece, 2010.

6. RAE; HTSO/DESMIE; PPC. 'Development Study of Crete Power System-Interconnection to mainland System'; Technical Report; Regulatory Authority for Energy (RAE): Athens, Greece, 2011. (In Greek)

7. Kabouris, J.; Tsirekis, K.; Georgopoulos, A.; Aravanis, I. The interconnection of the Cycladic islands: A major innovative transmission project for the Greek EPS. In Proceedings of the 2016 Cigre 1st South-East European Conference (SEEC), Portoroz, Slovenia, 7-8 June 2016. 
8. Spathis, D.; Lorentzou, M.; Prousalidis, J.; Tsirekis, K.; Kabouris, J. Transient and resonant overvoltages during the operation of 150 kV Lavrio-Syros interconnection. In Proceedings of the IET 2016 MedPower Conference, Belgrade, Serbia, 6-9 November 2016.

9. Decision 785/2019. Determination of the Cost-Effective Operation of the Electrical Systems of the a) South and West Cyclades and b) South and North Aegean Non-Interconnected Islands, in Accordance with Article 108A of Law 4001/2011; Regulatory Authority of Energy: Athens, Greece, 2019. (In Greek)

10. Kabouris, J.; Nanou, S.; Papathanasiou, S.; Pitas, C. Technical and economic feasibility analysis of Aegean island inter-connections to the Mainland Grid. In Proceedings of the 2020 CIGRE e-Session, Paris, France, 24 August-3 September 2020.

11. Vrana, T.K.; Mo, O. Optimal operation voltage for maximal power transfer capability on very long HVAC cables. In Proceedings of the 2016 13th Deep Sea Offshore Wind R\&D Conference (EERA DeepWind'2016), Trondheim, Norway, 20-22 January 2016.

12. Skaanoey, T.; Kerin, U.; Van Luijk, N.; Thibaut, E. AC subsea power transmission architectures, design and challenges, the Martin Linge case. In Proceedings of the 2017 Offshore Technology Conference, Houston, TX, USA, 1-4 May 2017.

13. Lauria, S.; Palone, F. Optimal operation of long inhomogeneous AC cable lines: The Malta-Sicily interconnector. IEEE Trans. Power Deliv. 2014, 29, 1036-1044. [CrossRef]

14. Gatta, F.M.; Geri, A.; Lauria, S.; Maccioni, M. Steady-state operating conditions of very long EHV AC cable lines. Electr. Power Syst. Res. 2011, 81, 1525-1533. [CrossRef]

15. Lauria, F.; Gatta, M.; Colla, L. Shunt compensation of EHV cables and mixed overhead-cable lines. In Proceedings of the 2007 IEEE Lausanne Power Tech Conference, Lausanne, Switzerland, 1-5 July 2007.

16. Lobato, E.; Sigrist, L.; Rouco, L. Value of electric interconnection links in remote island power systems: The Spanish Canary and Balearic archipelago cases. Electr. Power Energy Syst. 2017, 91, 192-200. [CrossRef]

17. Colla, L.; Lombardo, L.V.; Kuljaka, N.; Zaccone, E. Submarine projects in the Mediterranean Sea. Technology developments and future challenges. In Proceedings of the 2016 1st Southeast European Regional CIGRÉ Conference, Portoroz, Slovenia, 7-8 June 2016.

18. Spathis, D.; Boutsika, T.; Prousalidis, J.; Tsirekis, K.; Kabouris, J.; Georgopoulos, A. Zero missing effect transient analysis on the $150 \mathrm{kV}$ AC interconnection between Crete and Peloponnese. In Proceedings of the 2018 IEEE International Conference on High Voltage Engineering and Application (ICHVE), Athens, Greece, 10-13 September 2018; pp. 1-4.

19. Kabouris, J.; Nomikos, V. A dynamic stability and security assessment study for the interconnection of Crete with the Hellenic mainland system via an 150 kV/AC network. In Proceedings of the 2016 IET Med-Power Conference, Belgrade, Serbia, 69 November 2016.

20. Kabouris, J.; Karystianos, M.; Nomikos, B.; Tsourakis, G.; Mantzaris, J.; Sakellaridis, N.; Voumvoulakis, E. Power system static and dynamic security studies for the 1st phase of Crete island interconnection. J. Energy Energ. 2018, 67, 33-43.

21. Chatzipanos, M.; Margaris, I.; Tsirekis, K.; Katemliadis, S. Cable design for deep water applications and low losses transmission links: First project experience. In Proceedings of the 2020 CIGRE e-Session, Paris, France, 24 August-3 September 2020.

22. Karystianos, M.; Kabouris, J.; Koronides, A.; Sofroniou, S. Operation of the electrical system of Crete in interconnection with the mainland grid: A stability study. In Proceedings of the 2013 IX-IREP Symposium—Bulk Power System Dynamics and Control, Rethymnon, Greece, 25-30 August 2013.

23. Nanou, S.; Papadopoulos, M.; Papathanassiou, S. Assessment of island interconnection projects via HVDC links of partial capacity: The case of Crete. In Proceedings of the 2016 Cigre Session, Paris, France, 22-26 August 2016.

24. Nanou, S.I.; Psarros, G.N.; Papathanassiou, S.A.; Papadopoulos, M.P. Operating reserve scheduling for island systems with parallel AC-DC interconnectors: The case of Crete. In Proceedings of the 2017 IEEE PowerTech Conference, Manchester, UK, 18-22 June 2017.

25. Nanou, S.I.; Papathanassiou, S.A. Frequency control of island VSC-HVDC links operating in parallel with AC interconnectors and onsite generation. IEEE Trans. Power Deliv. 2018, 33, 447-454. [CrossRef]

26. Hatziargyriou, N.; Margaris, I.; Stavropoulou, I.; Papathanassiou, S.; Dimeas, A. Non-interconnected island systems: The Greek case. IEEE Electrif. Mag. 2017, 5, 17-27. [CrossRef]

27. Centre for Renewable Energy Sources and Saving (CRES), Greece: Wind Map of Greece. Available online: https: / geodata.gov. gr/en/dataset/aiolikos-khartes-tes-elladas (accessed on 18 May 2021).

28. Katopodis, T.; Markantonis, I.; Politi, N.; Vlachogiannis, D.; Sfetsos, A. High-Resolution Solar Climate Atlas for Greece under Climate Change Using the Weather Research and Forecasting (WRF) Model. Atmosphere 2020, 11, 761. [CrossRef]

29. Mendrinos, D.; Choropanitis, I.; Polyzou, O.; Karytsas, C. Exploring for geothermal resources in Greece. Geothermics 2010, 39, 124-137. [CrossRef]

30. Cigré Study Committee B4. HVDC Planning, Technology Selection and Specification, (CIGRE Tutorial TR007); Cigré: Paris, France, 2018; pp. 1-77.

31. Cigré Working Group B4.52. HVDC Grid Feasibility Study, (CIGRE Techn. Brochure 533); Cigré: Paris, France, 2013 ; pp. 1-189.

32. Cigré Working Group B1.47. Implementation of Long AC HV and EHV Cable Systems, (CIGRE Techn. Brochure 680); Cigré: Paris, France, 2017; pp. 1-190.

33. Cigré Working Group C4.502. Power System Technical Performance Issues Related to the Application of Long HVAC Cables, (CIGRE Tech. Brochure 556); Cigré: Paris, France, 2013; pp. 1-124. 
34. Zhang, X.-P.; Rehtanz, C.; Pal, B. (Eds.) Flexible AC Transmission Systems: Modelling and Control, 2nd ed.; Springer: Berlin/Heidelberg, Germany, 2012.

35. Panciatici, P.; Campi, M.C.; Garatti, S.; Low, S.H.; Molzahn, D.K.; Sun, A.X.; Wehenkel, L. Advanced Optimization Methods for Power Systems. In Proceedings of the 2014 IEEE 18th Power Systems Computation Conference (PSCC), Wroclaw, Poland, 18-22 August 2014.

36. National Grid ESO. Electricity Ten Year Statement 2015; Annex E: Technology; National Grid: London, UK, 2015.

37. Elliott, D.; Bell, K.R.W.; Finney, S.J.; Adapa, R.; Brozio, C.; Yu, J.; Hussain, K. A comparison of AC and HVDC options for the connection of offshore wind generation in Great Britain. IEEE Trans. Power Deliv. 2016, 31, 798-809. [CrossRef]

38. Cigré Working Group B4.55. HVDC Connection of Offshore Wind Power Plants, (CIGRE Techn. Brochure 619); Cigré: Paris, France, 2015; pp. 1-100.

39. IPTO. Ten-Year Network Development Plan (TYNDP) for the Period 2021-2030 (submitted for approval to RAE); Strategy and System Development Planning Department, IPTO: Athens, Greece, 2020. 